\title{
REPRESENTAÇÕES DE PROFESSORES SOBRE ADOLESCENTES ESTUDANTES DA ESCOLA PÚBLICA
}

\author{
REPRESENTATIONS OF TEACHERS ABOUT ADOLESCENTS STUDENTS OF THE \\ PUBLIC SCHOOL
}

\section{REPRESENTACIONES DE PROFESORES SOBRE ADOLECENTES ESTUDIANTES DE LA ESCUELA PÚBLICA}

\author{
Priscila Larocca* \\ Bianca Neves Prachum* \\ Natali de Fátima dos Santos ${ }^{* *+}$
}

\begin{abstract}
Resumo: A pesquisa busca conhecer e analisar representações sociais de professores sobre adolescentes da escola pública ao problematizar estereótipos, preconceitos e imagens sociais depreciativas e/ou patologizadoras dos jovens pobres, tal como veiculado nos últimos anos pelas mídias sociais perante as ocupações e manifestações estudantis em diferentes estados brasileiros. Fundamenta-se na Teoria das Representações Sociais de Moscovici e refuta vertentes naturalizantes e patologizadoras da Psicologia na compreensão do fenômeno da adolescência, adotando uma perspectiva histórico-cultural para entender como ocorrem as mudanças no psiquismo do adolescente em relação ao contexto social, cultural e histórico em que ele se insere. A partir de coleta de dados com 25 professores analisam-se os núcleos de significados encontrados em termos de frequência, percentual e ordenamento das manifestações docentes. Estes núcleos são: comportamento do aluno, motivação para aprendizagem, relação com o conhecimento, nível de desenvolvimento, perspectivas de futuro e relacionamento afetivo. Conclui-se que os participantes da pesquisa carregam representações negativas sobre os adolescentes das escolas públicas e está presente a visão de educação como disciplinamento e conformação, contribuindo para processos de exclusão da sociedade de classes, dominada pela ideologia do mérito e da difusão da liberdade individual. Daí a necessidade de imprimir na formação dos professores uma perspectiva crítica, que enfatize a complexidade e multideterminação dos fatores implicados no processo educacional e a necessária ruptura da imagem socialmente atribuída ao adolescente da escola pública
\end{abstract}

Palavras-chave: Representações sociais. Adolescência. Psicologia Histórico-Cultural. Formação de professores.

\begin{abstract}
The research seeks to know and analyze social representations of teachers about adolescents of the public school by problematizing stereotypes, prejudices and social images that are depreciative and / or pathologizing young poor, as it has been published in recent years by social media in relation to occupations and student demonstrations in different Brazilian States. It is based on the Theory of Social Representations of Moscovici and refutes the naturalizing and pathological aspects of Psychology in the understanding of the phenomenon of adolescence, adopting a historical-cultural perspective to

\footnotetext{
* Doutora em Educação. Docente do Departamento de Educação da Universidade Estadual de Ponta Grossa.

E-mail: prilarocca@gmail.com

** Mestranda em Educação na Universidade Estadual de Ponta Grossa. E-mail: biancanevesp@hotmail.com

*** Graduada em Pedagogia pela Universidade Estadual de Ponta Grossa. E-mail: psic.historicocultural@gmail.com
} 
understand how the changes occur in the psychism of the adolescent in relation to the social, cultural and historical context in which it inserts itself. From the data collection with 25 teachers, it analyzes the nuclei of meanings found in terms of frequency, percentage and order of teacher manifestations. These nuclei are: student behavior, motivation for learning, relationship with knowledge, level of development, future perspectives and affective relationship. It is concluded that the participants of the research carry negative representations on the adolescents of public schools and the education vision is present as discipline and conformation, contributing to processes of exclusion of class society dominated by the ideology of merit and the diffusion of individual freedom . Hence the need to print in the teachers' training a critical perspective that emphasize the complexity and multidetermination of the factors involved in the educational process and the necessary rupture of the image socially attributed to the adolescent of the public school.

Palavras-Chave: Social representations. Adolescence. Historical-Cultural Psychology. Teacher training.

Resumen: La pesquisa busca conocer y analizar representaciones sociales de profesores sobre adolescentes de la escuela pública al problematizar estereotipos, prejuicios e imágenes sociales despreciativas e/o patologizadoras de los jóvenes pobres, tal como vehiculado en los últimos años por las midias sociales ante las ocupaciones y manifestaciones estudiantiles en diferentes estados brasileños. Se fundamenta en la Teoría de las Representaciones Sociales de Moscovici y refuta vertientes naturalizantes y patologizadoras de la Psicología en comprensión del fenómeno de la adolescencia, adoptando una perspectiva histórico-cultural para entender cómo ocurren los cambios en el psiquismo del adolescente en relación al contexto social, cultural e histórico en que él se encere. A partir de colecta de datos con 25 profesores se analizan los núcleos de significados encontrados en términos de frecuencia, porcentual y ordenamiento de las manifestaciones docentes. Estos núcleos son: comportamiento del alumno, motivación para aprendizaje, relación con el conocimiento, nivel de desarrollo, perspectivas de futuro y relacionamiento afectivo. Se concluye que los participantes de la pesquisa cargan representaciones negativas sobre los adolescentes de las escuelas públicas y está presente la visión de educación como disciplina y conformación, contribuyendo para procesos de exclusión de la sociedad de clases, dominada por la ideología del mérito y de la difusión de la libertad individual. Ahí la necesidad de imprimir en la formación de los profesores una perspectiva crítica, que enfatice la complejidad y multi-determinación de los factores implicados en el proceso educacional y la necesaria ruptura de la imagen socialmente atribuida al adolescente de la escuela pública

Palabras Claves: Representaciones sociales. Adolescencia. Psicología Histórico-Cultural. Formación de profesores.

\section{Introdução}

A pesquisa que fundamenta o presente texto teve como objetivos conhecer e analisar representações sociais de professores sobre alunos adolescentes que estudam em escolas públicas ${ }^{1}$. Este tipo de estudo ganha

\footnotetext{
${ }^{1}$ A presente investigação integra-se ao Projeto de Pesquisa "Compreensões da adolescência para a formação de professores: buscando abordagens baseadas na Psicologia Histórico Cultural”. (LAROCCA, MACHADO, PRACHUM e SANTOS,
}

relevância quando se considera que os saberes e concepções que sustentam suas práticas educativas estão impregnados de representações que lhes dirigem a visão que tem dos seus alunos, do meio social em que estes vivem e até mesmo da função de educar. Tais representações sociais portadas pelos professores sobre os adolescentes e

2014). Também faz parte do Núcleo de Estudos, Pesquisas e Extensão em Pedagogia, Pedagogia Social e Educação Social - NUPEPES, desenvolvidos na Universidade Estadual de Ponta Grossa. 
jovens carregam explicações que se dão nas trocas cotidianas na vida social e na escola, compreendendo crenças, teorias implícitas, modelos de comportamento, formação de rótulos, estigmas e até mesmo preconceitos.

Atualmente, não é difícil observar a presença significativa de uma imagem social depreciativa dos jovens/adolescentes, especialmente daqueles que provém das classes populares que, por via de regra, são estudantes nas escolas públicas.

Em 2015 vimos a mídia noticiar intensa ação policial contra estudantes paulistas que ocupavam suas escolas para protestar contra a chamada "reorganização" do ensino do governo Alkmin. Durante boa parte daquele ano, estudantes, apoiados pelos docentes, fizeram greves, manifestações e ocuparam escolas contra a "reorganização" do ensino do Governo Alckmin, que implicaria fechamento de mais de 90 escolas e afetaria cerca de 300 mil alunos da rede, sem que isto fosse discutido com os interessados. A medida foi suspensa mediante a resistência dos prejudicados e a intervenção judicial do Ministério Público.

Em 2016, estudantes de São Paulo voltaram a se manifestar diante da precariedade do funcionamento das escolas e em face da divulgação de corrupção nas verbas destinadas a merenda escolar. No Rio de Janeiro também houve manifestações dos estudantes das escolas públicas. Nos dois estados verificou-se intervenção excessivamente repressora da polícia contra os estudantes, obviamente justificada pela mídia como necessária.

Também em 2016 ocorreram ocupações das escolas, protestos e resistência estudantil contra as medidas tomadas pelo governo pós-golpe em relação a implantação, sem participação popular, da reforma do ensino médio (Medida Provisória 746/2016) e contra a aprovação da chamada "PEC do Teto" Proposta de Emenda Constitucional 241, que suprimiu investimentos do governo em educação e em outras áreas pelos próximos 20 anos. Este movimento estudantil iniciado no estado do Paraná, embora fortemente reprimido pelo governador Beto Richa estendeu-se para outros estados, suscitando atenção da mídia que transmitiu para a população constantemente ideias pejorativas dos jovens estudantes tidos como rebeldes, marginais, violentos, agressivos, preguiçosos etc.

Tal cenário social e político converge para as motivações que sustentaram a proposição do projeto, presentes nas percepções de professores em formação continuada acerca do modo pelo qual estes representam alunos adolescentes, mais particularmente os que estudam em escolas públicas, descritos frequentemente de maneira estereotipada, a partir de uma imagem depreciativa e/ou patologizadora. Em tais percepções, os alunos aparecem como delinquentes, traumatizados, revoltados, sempre prontos a confrontar a autoridade docente, ou apresentar comportamentos inadequados ou problemáticos na escola e na sala de aula devido a um desinteresse "natural” pelos estudos, atribuído frequentemente à ebulição hormonal e ao despertar da sexualidade genital.

Encontramos também semelhantes estereótipos sobre a juventude no imaginário da sociedade, coisa que a mídia se encarrega de fortalecer. Checcia e Souza (2014) afirmam que houve, em nosso contexto, a partir de 1990, uma representação social atribuída à juventude predominantemente marcada por referências à violência, transgressões, problemas de comportamento e atitudes desajustadas socialmente. As autoras mencionam Abramo (1997), que se refere a uma imagem social ameaçadora na qual a juventude é depositária do medo social, pois encarna possibilidades de ruptura da ordem estabelecida e do status quo. 
Checcia e Souza também ressaltam que a Psicologia contribuiu para a formação desta imagem social negativa e preconceituosa, que encontraram em pesquisa com estudantes de 14 a 16 anos, da rede estadual de São Paulo. Notemos o que dizem:

[...] vistos como transgressores, delinquentes, rebeldes, violentos ou vândalos, os jovens são frequentemente associados à criminalidade, drogadição ou comportamentos antissociais. Tais estereótipos são veiculados pela opinião pública, propagados pelos meios de comunicação e endossado por produções acadêmicas, tendo, inclusive, a Psicologia como aliada na legitimação dessa imagem estereotipada [...] (CHECCIA; SOUZA, 2014, p. 107).

Acrescentemos a esta imagem, outra que vê o jovem pobre como marginal. A mesma pesquisa mostra que, dentro da escola, uma intensifica-se o estereótipo ameaçador da juventude, quando se trata de jovens oriundos das classes populares. Enfatizemos com Sposito:

De um lado, associamos violência, marginalidade, à pobreza, como se esses termos exprimissem uma relação linear de causa e efeito [...]; de outro, não buscamos compreender, quando a violência e a marginalidade se fazem presentes, os seus significados para um enorme contingente da população a quem se retirou o direito de projetar o futuro, apresentando somente o não-emprego, o não-salário, a ausência de direitos e de espaços de convivência cultural como alternativas de vida. (SPOSITO, 1996, p. 100 apud CHECCIA; SOUZA, 2014, p. 110).

Ora, esta imagem social dos jovens pobres, depreciativa e negativa, amplamente reforçada pela mídia, é observada nas repressões policiais cada vez mais ostensivas aos estudantes, inclusive no interior das escolas públicas. Vemos, portanto, que o contexto atual traz razões suficientes para justificar o estudo a que nos propusemos.

Assim, este artigo se referencia nos estudos sobre representações sociais, e sobre a adolescência na abordagem histórico-cultural, que se apresentam a seguir para então descrever, analisar e discutir os dados encontrados na pesquisa.

\section{Os estudos sobre representações sociais e suas contribuições para a formação docente}

Em 1961, Serge Moscovici criava o termo "representações sociais" em sua obra La Psychanalyse: son image et son public, dando início a um longo processo de elaboração da Teoria das Representações Sociais. Ao buscar redefinir o campo da Psicologia Social, Moscovici considerou a função simbólica e o poder de construção do real que as representações sociais possuem, sendo que para isso retomou e criticou o conceito de "representação coletiva”, proposto pela sociologia de Emile Durkheim.

Na concepção durkheimiana, as representações coletivas correspondem a um corpo de significados acionados pelos indivíduos nas trocas sociais, funcionando como uma espécie de "consciência ou memória coletiva", fonte referencial para os comportamentos individuais. Durkheim entendia que as representações dominantes na sociedade impor-se-iam aos indivíduos na vida social, atuando como recursos de identificação, coesão e sobrevivência dos grupos sociais. (ALEVATO, 1999). Alves-Mazzotti (2008) explica que o conceito durkheineano referia-se a uma classe muito ampla e estática de fenômenos psíquicos e sociais, que não considerava os processos pelos quais as representações se constituíam, nem a diversidade de modos de organização 
do pensamento humano. Segundo a autora, Moscovici procurava elaborar um conceito verdadeiramente psicossocial, capaz de dialetizar as relações entre indivíduo e sociedade e superar o generalismo e a ausência de dinamismo que o conceito de Durkhein apresentava. Com efeito, Moscovici destacou em suas críticas dois aspectos centrais:

1. falta de preocupação em se buscar a origem da generalidade dos fenômenos que o conceito de Representação Coletiva engloba: a ciência, a religião, os mitos, a ideologia entre outros fenômenos sociais ou psíquicos;

2. a ausência da dinâmica das Representações Coletivas que não a torna adequada aos estudos de sociedades complexas como a nossa onde existe pluralidade de sistemas envolvidos (políticos, filosóficos, religiosos, entre outros) e uma alta rotatividade do fluxo de representação. (BELLINI; REIS, 2011, p. 150).

Ao superar tais simplificações, a Teoria das Representações Sociais constitui-se uma perspectiva para fazer uma leitura crítica e desvelar a complexidade dos fenômenos do mundo social, em suas trocas. AlvezMazzotti), nesse sentido, ressalta que não há dicotomia entre o universo interior e exterior, entre a atividade psicológica representativa do sujeito e o mundo em que vive. Observe-se:

[...] no caso das representações sociais, parte-se da premissa de que não existe separação entre o universo externo e o universo interno do sujeito: em sua atividade representativa, ele não reproduz passivamente um objeto dado, mas, de certa forma, o reconstrói e, ao fazê-lo, se constitui como sujeito, pois, ao apreendê-lo de uma dada maneira, ele próprio se situa no universo social e material. (ALVEZ-MAZZOTTI, 2008, p. 23).

Há, portanto, que se considerar o movimento dialético entre sujeito e objeto, entre o mundo cognitivo e o mundo social, pois, é por meio de influências recíprocas que se constituem as representações sociais.

Pesquisadores como Spink (1993), Jovchelovitch (1998), Jodelet (2001), entre outros, contribuíram para aprofundar a Teoria das Representações Sociais de Moscovici. No que diz respeito ao campo teórico, o conceito de representações sociais formulado por Spink compreende-as como:

[...] formas de conhecimento que se manifestam como elementos cognitivos - imagens, conceitos, categorias, teorias -, mas que não se reduzem jamais aos componentes cognitivos. Sendo socialmente elaboradas e compartilhadas, contribuem para a construção de uma realidade comum, que possibilita a comunicação. (SPINK, 1993, p. 300).

Compreendem-se, então, as representações sociais como fenômenos ao mesmo tempo individuais e coletivos, cujos conteúdos só podem ser mais bem entendidos a partir de seus contextos de produção.

Na Teoria das Representações Sociais, Moscovici mostra que o compartilhamento de ideias, pensamentos e concepções criadas sobre determinados objetos, formam as representações. Os principais objetivos dessas criações são a compreensão e a interpretação do objeto. Por isso, são sempre de alguém sobre algo, que pode ser outro sujeito. (SÁ, 1993).

As representações sociais criadas nem sempre são reais. São conhecimentos práticos resultantes das relações interpessoais. Normalmente são compartilhadas em um mesmo grupo social, no qual os sujeitos acabam influenciando uns aos outros com suas 
ideias, crenças, cultura e suas próprias experiências de vida. (SÊNA, 2000). Os sujeitos compartilham suas interpretações sobre determinados objetos do seu ponto de vista psicológico e social, dependendo dos sujeitos com os quais convivem e com as informações que recebem nas instituições que frequentam ou das mídias. Essas informações podem ser de cunho científico ou apenas do senso comum. (JODELET, 1993).

Quatro características ao ato de representar, conforme Jodelet (2001) devem ser destacadas: a) toda representação social é sempre representação de alguma coisa (objeto) e de alguém (sujeito); b) nas representações sociais, o objeto é substituído por uma simbolização, a qual é interpretada segundo um sistema de significações; c) a representação social é uma forma de saber ou conhecimento; d) esse saber é prático, porque produzido na experiência, em dados contextos e condições de produção.

Pode-se dizer, então, que a Teoria das Representações Sociais focaliza a produção de saberes sociais, saberes esses que circulam na vida cotidiana e são partilhados entre as pessoas a fim de tornar aquilo que é não-familiar, em algo familiar. Na concepção moscoviciana, os universos familiares são consensuais, pois as ideias e interpretações confirmam crenças e compreensões já existentes. O não-familiar é o universo do novo, da perturbação aos sistemas de referência dos indivíduos, gerando, por isso, conflito e tensão. (REIS; BELLINNI, 2011).

Além da função de saber prático, na dinâmica das relações e práticas sociais, as representações sociais também cumprem funções de identidade social, orientação ou prescrição para as ações e justificação. Ao exercer tal função identitária, as representações sociais situam os indivíduos e grupos no campo social, permitindo-lhes elaborar uma identidade pessoal e social. Através da função de orientação, fornecem guias para os comportamentos, apresentando-se como espécie de prescrição das condutas, pois se impõem sobre os indivíduos definindo o que é aceitável para determinado contexto social. A função justificadora visa manter e justificar diferenças sociais através de explicações posteriores a comportamentos e decisões. (ABRIC, 2000 apud REIS; BELLINNI, 2011).

Os processos pelos quais as representações sociais se constituem nos indivíduos são a ancoragem e a objetivação.

A ancoragem, segundo Alvez-Mazzotti (2008, p. 29), consiste na “[...] integração cognitiva do objeto representado no sistema de pensamento preexistente e às transformações que, em consequência, ocorrem num e noutro". Isto equivale a dizer que tudo aquilo que é estranho, perturbador, diferenciado, será inserido "organicamente” ao universo de saberes, esquemas, ideias e relações já existentes na cognição do sujeito, o que significa que “[...] a representação sempre se constrói sobre um já pensado, manifesto ou latente.” (ALVEZ-MAZZOTTI, 2008, p. 30). Por meio da ancoragem, aquilo que é estranho ou novo, ao ser assimilado ao universo familiar, passa a ser classificado, rotulado, comparado, categorizado, podendo fazer confirmar quadros de pensamento habituais, cristalizados ou antigos. Esse processo corresponde à atribuição de sentido que o sujeito cognoscitivo realiza sobre um objeto estranho que lhe exige posicionamento. Entram em questão aí as escalas de valores, as normas, as hierarquizações existentes e prevalentes na sociedade, que vão tecer em torno daquilo que é estranho uma rede de significados através dos quais o novo será inserido e avaliado. Alevato explica que no processo de ancoragem:

Ao explicar o novo, este passa a fazer parte de uma matriz de identidade, sendo assim, 
classificado numa escala de valores, caracterizados, convencionados e hierarquizados. Não se trata, como poderia parecer, de uma operação ditada pelas normas científicas ou pela lógica formal; é uma lógica própria, dependente do momento histórico e de cada formação ou grupo cultural. (ALEVATO, 1999, p. 93).

É, portanto, por meio da ancoragem que o processo de familiarização acontece na cognição do sujeito, permitindo-lhe suportar as tensões causadas pelo novo.

A objetivação, segundo explica Spinck (1993, p. 306), “é essencialmente uma operação formadora de imagens, o processo através do qual noções abstratas são transformadas em algo concreto, quase tangível [...]”. Pela objetivação o sujeito elabora conceitos e imagens, a fim de reproduzir a representação social no mundo exterior. É um processo direcionado para fora ou para as outras pessoas e possui três fases: a construção seletiva, a esquematização estruturante e a naturalização. O sujeito, ao se apropriar de informações novas sobre um dado objeto, realiza a construção seletiva como quem faz uma triagem, retendo e/ou ignorando seus elementos, a partir de critérios e normas do mundo circundante. Pela esquematização o sujeito organiza em sua mente um "núcleo ou esquema figurativo", isto é, uma imagem coerente, uma estrutura conceitual facilitada. Esse núcleo figurativo será naturalizado pelo sujeito, ou seja, suas imagens serão transformadas em sua cognição em elementos da realidade, sendo a partir daí difundidas nas trocas sociais. (ALVEZMAZZOTTI, 2008).

A objetivação, portanto, é o processo de materialização do objeto, sendo como um percurso para interpretá-lo. Neste, o objeto é duplicado em nossa mente, e há um início de busca de maneiras para compreender e naturalizar o mesmo. (SÁ, 1993).
Como se pode perceber, pelo seu potencial interpretativo, a Teoria das Representações Sociais apresenta-se como uma importante ferramenta de compreensão e análise na pesquisa em educação. (CRUZOÉ, 2004). Aliás, registram Menin; Shimizu; Lima, (2009, p. 551) que: “[...] a teoria tem sido extremamente útil para revelar as relações entre conhecimentos práticos e desempenho de papéis e de funções na escola, de um lado, e questões ideológicas, políticas, pedagógicas no campo da educação, de outro.” Em artigo intitulado “A Teoria das Representações Sociais nos estudos sobre representações de professores", as pesquisadoras examinaram 27 teses e dissertações de programas de pós-graduação brasileiros, constatando que:

As pesquisas que têm como objeto de estudo as representações dos professores a respeito dos seus alunos, ligadas a temas e contextos específicos, procuram identificar como essas representações podem estar ancoradas nas experiências cotidianas, em modelos sociais vigentes ou no conhecimento científico, e a possível influência dessas representações na relação do professor com seus alunos e na prática pedagógica. (MENIN; SHIMIZU; LIMA, 2009, p. 551).

Ora, este é o caso da pesquisa que foi desenvolvida para melhor conhecer e analisar representações sociais de professores sobre alunos adolescentes que estudam em escolas públicas. Cabe, então, a seguir, refletir sobre o fenômeno da adolescência, buscando superar representações naturalizantes e universalizantes, que centram no desenvolvimento biológico a explicação dos comportamentos, problemas e desafios que os adolescentes estão a colocar para os professores em nossas escolas, em favor de uma abordagem histórico-cultural, que considere o contexto real em que o desenvolvimento do jovem se dá. 


\section{Contribuições da Psicologia à compreensão do fenômeno adolescência: das perspectivas naturalizantes à Psicologia Histórico- Cultural}

A Psicologia Histórico-Cultural teve sua origem na União Soviética, no início do século XX, fundamentada no Materialismo Histórico-Dialético. Para a Psicologia Histórico-Cultural, o ser humano se desenvolve histórica e culturalmente de forma ilimitada, na medida em que se apropria, no decorrer do tempo, da cultura construída em sociedade. Em relação a isso, Leontiev (1978 apud ANJOS, 2013, p. 25), acrescenta:

Podemos dizer que cada indivíduo aprende a ser um homem. O que a natureza lhe dá quando nasce não lhe basta para viver em sociedade. É- lhe ainda preciso adquirir o que foi alcançado do decurso do desenvolvimento histórico da sociedade humana.

Este processo de humanização da natureza e do próprio ser humano se dá através da atividade fundante do mundo dos homens: o trabalho. É justamente essa capacidade de transformação da natureza que diferencia o homem do animal. Nesse sentido, Duarte e Saviani afirmam que a atividade vital do humano, se diferencia das de outras espécies por,

[...] ser uma atividade consciente que objetiva em produtos que passam a ter funções definidas pela prática social. Por meio do trabalho o ser humano incorpora de forma historicamente universalizadora, a natureza ao campo dos fenômenos sociais. Nesse processo, as necessidades humanas ampliam- se, ultrapassando o nível das necessidades de sobrevivência e surgindo necessidades propriamente sociais. (grifos no original). (DUARTE; SAVIANI, 2010 apud ANJOS, 2013, p. 27).
Outro aspecto diferencial das atividades conscientes do homem diz respeito a um traço característico do homem, defendido por Luria (1979), que afirma que grande parte dos conhecimentos e habilidades do homem se constitui a partir da assimilação da experiência comum a toda a humanidade, a qual é acumulada histórica e socialmente para que seja transmitida através de processo de aprendizagem. (ANJOS, 2013).

A Psicologia Histórico-cultural investiga, pois, o desenvolvimento humano, considerando as condições histórico-sociais existentes por detrás desse processo. Nesse sentido, a adolescência é considerada um fenômeno produzido pela humanidade. Leal e Facci (2014, p. 19) asseveram que o fenômeno da adolescência traduz as características históricas e culturais da sociedade capitalista do século XX, não tendo existido até este momento. Assim, a adolescência não pode ser compreendida como "algo natural, ligado à maturação biológica” (LEAL; FACCI, 2014, p. 19), nem como fenômeno universal, comum a todos os seres humanos de forma padronizada.

A partir das bases materiais presentes na sociedade capitalista o fenômeno da adolescência começou a se constituir tal como é no modelo atualmente conhecido. Alguns elementos característicos dessa sociedade foram essenciais para a construção do fenômeno da adolescência, como é o caso da universalização da educação (LEAL; FACCI, 2014), que ocasionou a liberação das crianças do processo produtivo. Manacorda, retratando as mudanças que ocorreram na sociedade no século XVIII, assinala que,

[...] com o deslocamento de grandes massas de camponeses para as cidades e com a mudança das oficinas artesanais para as fabricas, iniciavam- se grandes transformações culturais, com conflitos sociais e 
revoluções morais que provocaram novas exigências e mudanças nas condições de formação dos homens, ampliando o papel da instituição escolar para atender essas novas exigências. (MANACORDA, 2006 apud LEAL; FACCI, 2014, p. 20).

Com a necessidade de empregar os adultos e diminuir tensões causadas pelo desemprego, deu-se o prolongamento da escolarização das crianças, retardando sua entrada no processo produtivo e levando a constituição de um novo grupo social. É nesse momento que pesquisadores começam a criar teorias a respeito desse período do desenvolvimento.

Muitas das pesquisas foram desenvolvidas a partir da Biologia, compondo uma concepção universalizante e naturalizante de desenvolvimento, que perdura até os diais atuais, a despeito de muitos outros estudos, baseados na Psicologia Histórico-Cultural, terem demonstrado que a transição da infância para a fase adulta não ocorre da mesma forma em diferentes sociedades. (ANJOS, 2013; AVILA, 2005; BOCK, 2004; TOMIO; FACCI, 2009).

A Psicologia Histórico-Cultural compreende a adolescência como um "processo dinâmico que pode transcorrer de diferentes maneiras”. (LEAL; FACCI, 2014, p. 22), em decorrência dos diferentes contextos. Porém, isso não significa desconsiderar as mudanças biológicas existentes nesse período, mas implica não considerá-las como se fossem únicas ou exclusivas desse processo.

Vygotsky (1996) apontou um grande erro da Psicologia Tradicional, que considerava que os elementos fundamentais do pensamento do adolescente já estariam presentes na criança desde os três anos de idade e iriam evoluindo de forma linear até a idade de transição. ${ }^{2}$ Afirmava que o desenvolvimento

2 Idade de transição é a designação utilizada por Vygotsky para o período da adolescência. psíquico é processo descontínuo marcado por transformações causadas por novas formações psíquicas e sociais as quais constituem uma nova estrutura da personalidade. Para ele, a adolescência é marcada por uma formação qualitativamente nova e apresenta mudanças essenciais nos processos do pensamento.

Diferentemente da visão evolutiva maturacional de desenvolvimento, a Psicologia Histórico-Cultural compreende que a atividade humana não é algo mecânico, mas acontece de forma dialética, regulando-se e estruturando-se de acordo com as novas mudanças dos mecanismos de aspirações e interesses. Essas novas formações, segundo Leal e Facci (2014), são diferentes em cada período do desenvolvimento, servindo como guia desse processo. Sendo assim, durante a adolescência, ocorre a formação das funções psicológicas superiores e de uma nova estrutura do pensamento as quais estão ligadas a reorganização da personalidade.

Vygotsky (1996, p. 36) ${ }^{3}$ afirmava ser um equivoco dar centralidade na adolescência às mudanças emocionais e toma-las como homogêneas e totalmente negativas. Segundo ele, “os processos do desenvolvimento em geral e o processo em particular, se distinguem, por uma configuração muito mais complexa, por uma estrutura muito mais delicada”. O ponto mais importante das mudanças que ocorrem nesse período reside na formação de novas necessidades biológicas e culturais superiores que orientam e redirecionam as mudanças dos mecanismos de interesse do adolescente.

Portanto, a existência de crises na adolescência passa a ser explicada pelo

\section{(VYGOTSKI, 1996).}

3 “los processos del desarrollo en general y el processo en particular, se distinguen, por una configuración mucho más compleja, por una estructura mucho más delicada." 
"redirecionamento do desenvolvimento". (LEAL; FACCI, 2014, p. 24). As mudanças no comportamento do adolescente e a mudança do desenvolvimento dos interesses, ao mesmo tempo em que se dão em linhas diferentes, se correlacionam "explicando as principais peculiaridades do desenvolvimento". (VYGOTSKY, 1996, p. 30). Assim, os períodos de crise correspondem ao abandono de determinados comportamentos e formas de pensar, pelo adolescente, uma vez que os mesmos já não respondem às suas novas necessidades. Sendo assim, os interesses determinam a estrutura e a dinâmica da cada período do desenvolvimento, implicando a necessidade de adquirir novos conhecimentos, a fim de suprir suas novas necessidades. Como complementam Leal e Facci (2014, p. 26),

[...] e para tal, será preciso internalizar o que antes era externo, como as convicções, os interesses, a concepção de mundo, as normas éticas, as regras de conduta, os ideais, os esquemas de pensamento. Os novos estímulos que surgem nessa etapa impulsionam o desenvolvimento e os mecanismos do pensamento.

É na adolescência, portanto, que se manifestam relações entre as necessidades biológicas do organismo e as necessidades culturais superiores que provém do contexto cultural e social em que o adolescente está inserido, os quais irão orientar os seus interesses. Os conteúdos das atividades intelectuais do adolescente não ocorrem graças à maturação das formas biológicas das funções elementares e superiores, mas, e principalmente, devido a mudanças nas formas historicamente condicionadas da atividade intelectual. (VYGOTSKY, 1996).

De acordo com Leal e Facci (2014, p. 25), o contexto histórico-social influencia "o conteúdo concreto de um estágio de desenvolvimento e o desenvolvimento psíquico como um todo”. Em razão disso, a Psicologia Tradicional se equivoca ao assinalar a adolescência como fenômeno universal comum a toda a humanidade (BOCK, 2014), sendo necessário compreender que, ao mesmo tempo em que ocorrem mudanças no desenvolvimento orgânico biológico do adolescente, estas estão totalmente relacionadas ao desenvolvimento histórico e cultural do sujeito.

Além da ruptura e desaparecimento dos interesses infantis, a adolescência, de acordo com Vygotsky (1996), é influenciada pela maturação biológica sexual, a qual, embora aconteça, não é compreendida como central. A Psicologia Histórico-Cultural. considera, apenas, que a maturação sexual acarreta "novos impulsos no sistema de atrações orgânicas”, influenciando a mudança de interesses e o desenvolvimento social da personalidade. (LEAL; FACCI, 2014, p. 26). É importante considerar que na mesma medida em que acontece o desenvolvimento da personalidade do adolescente, também ocorre o seu desenvolvimento social. É a relação entre esses dois processos que leva a reestruturação da personalidade, no sentido de transformação nos "interesses humanos que se convertem em momentos internos integrantes da personalidade”. (LEAL; FACCI, 2014, p. 26). Assim sendo, os interesses ligam-se às novas necessidades do adolescente e se desenvolverão a partir do confronto com as forças culturais presentes no contexto, modificando-se. Neste confronto, os interesses do adolescente se desenvolverão na direção de uma maior consciência, pois vão tomando formas superiores, mais elaboradas e conscientes, distinguindo-se de uma mera atração orgânica, instintiva. Vygotski explica sobre isso que:

[...] o desenvolvimento dos interesses subjaz ao desenvolvimento cultural e psíquico do adolescente; o interesse em sua forma superior, ao fazer-se consciente e livre se 
apresenta para nós como uma aspiração consciente, uma atração para si diferente do impulso instintivo que é uma atração em si. ${ }^{4}$ (VYGOTSKI, 1996, p. 22).

Os novos interesses colocam em marcha e alteram os mecanismos do comportamento do adolescente. Nas palavras de Vygotsky,

Continuam existindo os mecanismos do comportamento já formados, surgem à base deles outros novos, porém os interesses, assim dizendo, as necessidades que colocam em andamento esses mecanismos mudam radicalmente. Não compreendemos nada no desenvolvimento psíquico do adolescente se não levamos em consideração este fato fundamental ${ }^{5}$. (VYGOTSKI, 1996, p. 23).

Disto resulta que ideias que antes não interessavam ao sujeito integram-se durante a adolescência como parte de sua personalidade, sustentando o surgimento de novos interesses. Há, portanto, uma mudança nas motivações que impulsionam o sujeito a desempenhar determinada atividade, mudando consequentemente o seu lugar no sistema de relações sociais. A passagem da atividade principal da infância (brincar) para a atividade principal da adolescência (comunicações/relações mais íntimas com os pares e atividade conjunta dirigida ao futuro/estudo) se constrói

\footnotetext{
${ }^{4}$ El desarrollo de los intereses subyace en el desarrollo cultural y psíquico del adolescente; el interés en su forma superior, al hacerse consciente y libre se presenta ante nosotros como una aspiración consciente, una atracción para sí a diferencia del impulso instintivo que es una atracción hacia sí.

5 Continuán existiendo los mecanismos del comportamiento ya formados, surgen a base de ellos otros nuevos, pero los interesses, es decir, las necesidades que ponen en marcha esos mecanismos cambian radicalmente. No comprendemos nada en el desarrollo psíquico del adolescente si no tomamos en consideración este hecho fundamental.
}

sob as condições concretas de vida”. (LEAL; FACCI, 2014, p. 26). As pressões sociais e os novos interesses orientarão a mudança na atividade durante a idade de transição. A respeito disso Leal e Facci assinalam que,

Para o adolescente, essa passagem, ou transição, está associada a uma inclusão nas formas de vida social acessíveis a ele, como o envolvimento em certos encargos ou atividades sociais que não são mais de caráter infantil. Altera-se o lugar que ele ocupa na vida dos adultos que o rodeiam, nos negócios da família. Sua capacidade física, seu conhecimento e suas habilidades podem lhe aproximar, ou coloca-lo em condições de igualdade com os adultos. (LEAL; FACCI, 2014, p. 26).

A compreensão dos comportamentos adolescentes passa então pelas transformações em suas atividades principais ou dominantes. Baseando-se em Elkonin (1987 apud LEAL; FACCI, 2014), Vygotsky aponta a comunicação com os outros adolescentes e o estabelecimento de relações pessoais de caráter mais íntimo, como o cerne de tais atividades, uma vez que um adolescente compartilha relações pessoais com outro adolescente, num sentido de identificação e imitação de modelos adultos.

Para Vygotsky (1996, p. 54), as principais características da adolescência estão relacionadas diretamente à formação das funções psicológicas superiores e a formação do pensamento por conceitos. As funções psicológicas superiores (FPS) constituem o "núcleo fundamental da formação da personalidade". Determinadas funções se desenvolvem a partir do processo de socialização do sujeito e da aquisição de novos conceitos. Isto porque as mudanças que ocorrem no conteúdo do pensamento, de acordo com Tomio e Facci (2009, p. 96), estão atreladas a duas dimensões do comportamento "a do desenvolvimento das 
funções psíquicas elementares e as funções psíquicas superiores". Em relação a isso Vygotsky (1996, p. 60), afirma que o pensamento conceitual acontece por duas vias, uma referente às mudanças das funções e outra referente às novas tarefas colocadas ao pensamento do adolescente. Nas palavras de Tomio e Facci (2009, p. 96), “o pensamento é um processo de desenvolvimento cultural, histórico e socialmente condicionado”.

Vygotsky (1996, p. 63) assinala que na idade de transição, tudo aquilo que até então era exterior como “condições, interesses, concepção de mundo, normas éticas, regras de conduta, ideias, determinados esquemas do pensamento", nesse período é internalizado, pelo fato de que o adolescente passa por uma maturação no seu desenvolvimento e, ao mesmo tempo, o meio lhe impõe novas tarefas, que necessitam de um domínio de novos conteúdos, nascendo então "novos estímulos que impulsionam o desenvolvimento e os mecanismos formais de seu pensamento”. O conteúdo do pensamento se renova e se reestrutura, devido ao processo de formação de conceitos. O novo conteúdo impõe ao pensamento do adolescente nova forma de conduta. Esta renovação e reestruturação dos conceitos no pensamento do adolescente permite a ele desenvolver "a consciência social objetiva, o mundo da ideologia social”. (VYGOTSKY, 1996, p. 64). Assim, o sujeito adolescente ao ter contato com as esferas da vida cultural, além de poder assimila-las de forma completa e profunda, consegue realizar criativamente novas associações, devido à aquisição do pensamento em conceitos. Nas palavras de Vygotsky (1996, p. 64), o adolescente "participa ativamente nas diversas esferas da vida cultural que tem diante de si”. Através dessa afirmação, é possível compreender que na adolescência, o sujeito passa a desenvolver o pensamento crítico e se torna capaz de interpretar os nexos ocultos existentes por de trás dos fenômenos sociais. Isso se torna possível "graças ao aprofundamento e ampliação do conteúdo do pensamento”. (VYGOTSKY, 1996, p. 64).

Vygotsky (1996, p. 64), cita o pesquisador Pavel Petrovich Blonski (1884-1941) ${ }^{6}$ para explicar um importante aspecto em relação ao pensamento do adolescente, que diz respeito a sua autoconsciência, uma vez que esta ocorre a partir do momento em que ele amplia sua participação na produção social e compreende o lugar que ocupa nessa produção.

O pensamento do adolescente, de acordo com Vygotsky (1996, p. 70), está relacionado à formação da consciência de sua própria realidade interna. $\mathrm{O}$ adolescente passa a compreender não somente os demais, mas também a si mesmo. É justamente a compreensão de si e de suas próprias vivências, que permite a conversão para o pensamento por conceitos. Em relação a isso, Vygotsky (1996), escreve sobre a formação da psicologia de classes na adolescência, a qual consiste na percepção do adolescente a respeito da ideologia de classes sociais. A formação dessa percepção está relacionada à nova forma superior de atividade intelectual, caracterizada pela formação de conceitos e ao ambiente social em que o adolescente está inserido.

Esta forma de pensamento é resultado de sua colaboração com o contexto social que o rodeia. Envolve, portanto, a relação com um grupo social, com o qual divide experiências, atividades e interesses em comum, havendo uma identificação com determinada classe social. Vygotsky (1996, p. 66) a respeito disso afirma que, [...] a formação de conceitos abre diante ao adolescente o mundo da consciência social e impulsiona

\footnotetext{
${ }^{6}$ Relevante pedagogo y psicólogo soviético. Fue uno de los que intentaron basar la psicología em la filosofia marxista.
} 
inevitavelmente ao intenso desenvolvimento da psicologia e da ideologia de classes, a sua formação. ${ }^{7}$ Sendo assim, os conceitos presentes no pensamento do adolescente não se constituem apenas por um processo biológico, mas se "formam na esfera de uma determinada ideologia social”.

Portanto, percebe-se a importância de compreender como ocorrem as mudanças no psiquismo do adolescente, em relação ao contexto social em que ele se insere, aos grupos que se relaciona, pois estes exercem grandes influencias no desenvolvimento de sua personalidade.

\section{Metodologia, análise e discussão das representações sociais dos professores sobre os adolescentes da escola pública}

A pesquisa contou com 25 sujeitos participantes, originários de 5 municípios paranaenses diferentes (União da Vitória, Ponta Grossa, Ipiranga, Guarapuava e Castro), todos concursados pela Secretaria de Estado da Educação do Paraná, que ministram aulas em colégios estaduais que oferecem ensino médio e/ou pós-médio, educação geral e/ou profissionalizante. Todos eles ministram aulas no ensino médio, nível de escolaridade atingido, em geral, a partir dos 14 anos de idade. Dentre eles, apenas 3 participantes dão aulas também no ensino fundamental. A maior parte deles situa-se entre 30 e 50 anos de idade. $\mathrm{O}$ mais novo possui 31 anos e o mais velho 58. A maioria possui entre 2 e 13 anos de exercício da profissão.

A coleta de dados foi feita por meio da aplicação de um instrumento de pesquisa a

\footnotetext{
${ }^{7}[.$.$] la formación de conceptos abre ante el adolescente$ el mundo de la consciencia social e impulsa inevitablemente al intenso desarrollo de la psicología y la ideología de clases, a su formación.
}

professores durante a realização de um curso de formação pedagógica oferecido pela universidade. A primeira parte do instrumento consistiu no TCLE - Termo de Consentimento Livre e Esclarecido, junto ao qual se explicavam aos participantes sobre o objetivo da pesquisa e procedimentos, assegurando-lhes a liberdade de participação na mesma, bem como o sigilo sobre as fontes de dados. $\mathrm{Na}$ segunda parte, alocaram-se dados pessoais e, num espaço próprio, solicitou-se que escrevessem as dez primeiras expressões ou palavras que lhes viessem à mente para caracterizar os alunos adolescentes e jovens da escola pública. Tal solicitação fundamentou-se na técnica das associações ou evocações livres, a qual consiste em "apresentar uma palavra geradora às pessoas e solicitar que produzam expressões ou adjetivos que lhe venham à cabeça.” (COSTA; ALMEIDA, 1999 apud BELLINI; REIS, 2011, p. 154).

Após a coleta, os instrumentos de pesquisa foram numerados e analisados, sendo elaborada uma tabela auxiliar para registrar palavras-chave referentes às manifestações dos sujeitos, de conformidade com a ordem de prioridade que estes assinalaram e com a frequência de suas manifestações. Mediante constantes leituras e discussões entre os pesquisadores, as palavras-chaves foram agrupadas segundo semelhanças dos núcleos de significado depreendidos das manifestações. O critério de agrupamento das palavras-chave foi semântico e originou 06 núcleos de significados conforme o Quadro 1. 
Quadro 1: Núcleos de Significados, Frequência Total e Percentual das Manifestações dos Participantes

\begin{tabular}{l|l|l|l}
\hline \multicolumn{2}{l|}{ Núcleos de Significados } & Frequência & \% \\
\hline 01 & Comportamento do aluno & 59 & $29,94 \%$ \\
\hline 02 & Motivação para a aprendizagem & 42 & $21,31 \%$ \\
\hline 03 & Relação com o Conhecimento & 30 & $15,22 \%$ \\
\hline 04 & Nível de Desenvolvimento & 26 & $13,19 \%$ \\
\hline 05 & Perspectivas de Futuro & 24 & $12,18 \%$ \\
\hline 06 & Relacionamento Afetivo & 16 & $8,12 \%$ \\
\hline
\end{tabular}

Fonte: Dados dos autores

Cada núcleo de significados agrupou palavras ou expressões que convergiam sobre um dado aspecto da realidade tal como esta é lida/vivida/sentida/percebida por cada um dos docentes participantes da pesquisa em relação aos adolescentes com os quais convivem na escola.

A análise dos percentuais de frequência demonstra que mais da metade $(66,47 \%)$ das manifestações docentes se referiram aos três primeiros núcleos de significados (Comportamento do aluno, Motivação para a aprendizagem e Relação com o Conhecimento), tendo os núcleos 04, 05 e 06 (Nível de Desenvolvimento, Perspectivas de Futuro e Relacionamento Afetivo) menor relevância. Na verdade, se se considerar apenas o aspecto quantitativo, os dois primeiros núcleos juntos já atingem mais da metade das manifestações (51,25\%).

O Quadro 2 demonstra a frequência de representações em relação a ordem dos núcleos de significados, de conformidade com o que foi atribuído pelos participantes.

Quadro 2: Demonstrativo da Frequência de acordo com o Ordenamento dos Núcleos de Significados manifestados pelos Participantes.

\begin{tabular}{l|l|l|l|l|l|l|l|l|l|l|l|l|l}
\hline Núcleos de Significados & $1^{\circ}$ & $2^{\circ}$ & $3^{\circ}$ & $4^{\circ}$ & $5^{\circ}$ & $6^{\circ}$ & $7^{\circ}$ & $8^{\circ}$ & $9^{\circ}$ & $10^{\circ}$ & Frequência & $\%$ \\
\hline 01 & Comportamento do aluno & 10 & 5 & 4 & 5 & 7 & 7 & 5 & 6 & 6 & 4 & 59 & $29,94 \%$ \\
\hline 02 & $\begin{array}{l}\text { Motivação para a } \\
\text { aprendizagem }\end{array}$ & 9 & 1 & 5 & 1 & - & 6 & 2 & 4 & 2 & 2 & 42 & $21,31 \%$ \\
\hline 03 & $\begin{array}{l}\text { Relação com o } \\
\text { Conhecimento }\end{array}$ & - & 2 & 2 & - & 10 & - & 8 & 5 & 1 & 2 & 30 & $15,22 \%$ \\
\hline 04 & Nível de Desenvolvimento & - & - & 6 & 8 & 4 & 2 & - & 2 & 2 & 2 & 26 & $13,19 \%$ \\
\hline 05 & Perspectivas de Futuro & 4 & 2 & 1 & 4 & - & 3 & 4 & - & 4 & 2 & 24 & $12,18 \%$ \\
\hline 06 & Relacionamento Afetivo & - & - & 2 & 1 & 1 & 2 & 3 & 2 & 1 & 4 & 16 & $8,12 \%$ \\
\hline
\end{tabular}

Fonte: Dados dos autores

A visualização da ordem sequencial, tal como apresentada no Quadro 2, permite perceber que as representações dos núcleos
01, 02 e 05, respectivamente Comportamento do aluno, Motivação para a aprendizagem e Perspectivas de futuro, são aqueles que 
figuram desde as primeiras associações evocadas pelos professores ao tentarem caracterizar o aluno adolescente da escola pública.

No núcleo a que denominamos "Comportamento do aluno", os professores registraram as seguintes palavras-chave: indisciplinados (20), desrespeitosos (4), debochados (5), hiperativos (7), sem paciência (7), transgressores (6) inquietos (6) e ousados (4).

No segundo núcleo de significados, ao qual denominamos "Motivação para a aprendizagem”, identifica-se os seguintes registros: pouca iniciativa (11), pouco interesse (9), preguiçosos (9), desestimulados (5), falta de interesse (4), não ligados à disciplina escolar (2), desinteressados (2).

O terceiro núcleo de significados, que chamamos de "Relação com o Conhecimento" compõem-se das seguintes representações: vontade de aprender (10), questionam as coisas (7), conhecimento (5), curiosidade (4), gostam de discutir política em sala de aula (1), interessados (1), ligados à tecnologia (1), questionam teoria e prática (1).

Nos registros sobre os dois primeiros núcleos (comportamento e motivação) foram predominantes representações negativas, enquanto que o terceiro núcleo de significados (relação com o conhecimento) traz em sua maioria representações positivas. Nos dois primeiros núcleos de significados, os docentes marcaram mais aquilo que entendem que os adolescentes "não têm”: não tem disciplina, não tem respeito, não tem paciência, não seguem regras.

Sobre o comportamento verificaram-se registros como indisciplinados, desrespeitosos, debochados, hiperativos, inquietos e ousados que confirmam que tais representações estão ancoradas em concepções tradicionais de educação e de disciplina como cumprimento estrito e obediente às normas escolares. Tais registros fazem perceber que os docentes carregam uma visão ameaçadora e transgressora dos alunos, ancoradas numa expectativa pedagógica tradicional, em que se compreende o professor como responsável pelo pleno domínio e controle da disciplina escolar e permitem também supor que os docentes, antes mesmo de chegarem à escola, antecipam uma visão negativa do comportamento dos adolescentes da escola pública, que condizem com a construção social da ideia de adolescência como "crise” e "turbulência”, em que se esperam dos estudantes atitudes desviantes ou ameaçadoras à ordem vigente. Checchia e Souza tratam justamente desta questão, confirmando que na realidade brasileira:
A tematização social sobre os jovens (ou seja, a imagem socialmente atribuída à ju- ventude) a partir da década de 1990, no Brasil, é predominantemente marcada por referências à violência, associada à carac- terização da juventude como portadora 'problemas de comportamento', com ati- tudes desviantes em relação ao ajuste ou à integração social. (CHECCHIA; SOUZA, 2014, p. 106-107).

Neste imaginário desconsideram- se as razões pelas quais tais comportamentos se explicariam: a prática pedagógica, a didática docente, a normatização excessiva dentro da escola, a rotina, a mesmice, a precariedade das condições para a aprendizagem nas escolas públicas, a impossibilidade de uma relação pedagógica mais próxima em virtude do ensino de massas e da sobrecarga de trabalho docente, entre outros.

No que se refere às representações docentes negativas sobre a motivação para a aprendizagem dois aspectos convergem para a sua explicação na abordagem histórico-cultural. O primeiro, diz respeito ao desenvolvimento dos interesses e o segundo remete à atividade de estudar, tendo como base o seu 
sentido nesta sociedade concreta, pois o estudo é considerado por Vygotski como uma das atividades dominantes na idade de transição, ao lado da comunicação íntima pessoal.

Na abordagem vygotskiana, os interesses possuem uma natureza histórico-cultural e se constituem a partir dos interesses antigos, pois "os hábitos não mudam de maneira essencial ao longo de um ou dois anos". (KOSHINO, 2011, p. 64). Assim, os interesses (motivações) estão em pleno desenvolvimento durante a adolescência, podendo impulsionar a ação humana de modo positivo ou negativo. Os velhos interesses terão que ceder lugar aos novos, constituídos sob a sua base.

O adolescente começa a se interessar por objetivos completamente novos, perdendo o interesse pelas coisas que lhe interessava antes. Nesta fase, observa-se a existência de um complexo entrelaçamento dos processos de extinção e nascimento de novas necessidades em sua conduta. Este processo de extinção dos interesses infantis na idade de transição é, particularmente, longo, sensível e doloroso. (KOSHINO, 2011, p. 65).

Portanto, há coincidência do amadurecimento biológico com o desenvolvimento dos novos interesses, pois em nossa sociedade, é o ingresso do adolescente na fase das atrações orgânicas, que inaugura uma intensidade maior nas pressões culturais sobre o adolescente. (VYGOTSKI, 1996). O processo é doloroso e traz manifestações de irritabilidade, mudanças de humor, oscilações nas disposições, transcorrendo na medida em que o adolescente se confronta com necessidades culturais (por exemplo: de adentrar a vida adulta, ser independente, ingressar no mundo do trabalho, etc.), seguindo o mesmo ritmo do amadurecimento orgânico.

Este processo implica crises, contradições, negativismo, atitudes hostis, pois se inicia como manifestação negativa dos velhos interesses, em face das mudanças que se operam na posição que o adolescente ocupava no meio familiar e social. Contudo, tal crise não é natural e negativa, mas colocada como necessária ao desenvolvimento, pois resulta do confronto do adolescente com as exigências culturais e sociais e é inerente à constituição de uma nova fase mais estável de diferenciação dos interesses. Como diz Vygotski:

Se a fase de desenvolvimento dos interesses se encontra sob o signo das aspirações românticas, o final da mesma se distingue por uma eleição realista e prática de um interesse mais estável, que na maioria dos casos está diretamente vinculado a trajetória fundamental da vida, que tem elegido o adolescente. ${ }^{8}$ ( VYGOTSKI, 1996, p. 29).

Tudo isto implica efeitos diferenciados em relação às origens sociais dos adolescentes os quais estão na dependência das condições econômicas, sociais, culturais e políticas em que se dão as trajetórias concretas de vida dos jovens.

As ênfases negativas sobre o comportamento do aluno e a sua motivação para a aprendizagem fazem refletir sobre como o aluno se sente e se entende dentro do espaço escolar, cabendo perguntar: o quê daquele conjunto de sistemas simbólicos, carregados de elementos culturais, realmente faz sentido para estes sujeitos estudantes que vem de diversos outros espaços e se deparam com aquele território carregado de normas, regras, conteúdos e experiências? Por outro lado, as representações dos professores são também

\footnotetext{
${ }^{8} \mathrm{Si}$ la fase de desarrollo de los interesses se encuentra al príncípio bajo el signo de aspiraciones románticas, el final de la misma se distingue por una elección realista y práctica de un interés más estable, que en la mayoría de los casos está directamente vinculado a la trayectoria fundamental de la vida que ha elegido el adolescente.
} 
carregadas de sentido, pois permitem reconhecer como estes entendem que deveria ser a existência desses sujeitos dentro das escolas.

Salomone argumenta a partir de uma pesquisa realizada em uma escola de periferia que:

Para que possam garantir a própria autoridade, os professores percebem que há uma necessidade de reconhecimento dos seus discursos por parte dos alunos. Não há possibilidade de exercício da autoridade em sala de aula quando não se compreende ou se reconhece o que está sendo dito. O sucesso no interior da escola está, portanto, estreitamente vinculado à aptidão para o deciframento e o manejo e da linguagem escolar. Assim, na medida em que não se compreende o que o outro expressa, a ponte dialógica desmorona, dando lugar a enunciações atomizadas e desconectadas e enfraquecendo as relações de poder. (SALOMONE, 2009, p. 241).

É possível dizer a partir destas interpretações que existe um desequilíbrio entre as expectativas dos professores e dos alunos em relação ao sentido da escola e da atividade de estudar. Há, portanto, um distanciamento entre o que aluno pensa e entende sobre a escola e seus professores e o que estes pensam e entendem sobre seus alunos.

O conceito de atividade cunhado por Vygotsky e desenvolvido por Leontiev pode também explicar ou indicar como se constroem as visões dos professores sobre seus alunos. Mello nos explica que:

Leontiev, um pesquisador que trabalhou com Vygotsky e ajudou a desenvolver suas ideias, chama atividade não a qualquer coisa que a pessoa faça, mas apenas aquilo que faz sentido para ela. E quando uma tarefa adquire sentido para a pessoa que a realiza? Vejamos. Toda tarefa que a pessoa faz tem sempre um objetivo e um motivo. O objetivo é aquilo que deve ser alcançado no final da tarefa - seu resultado -, que já e previsto como uma ideia, antes do início da ação. O motivo e a necessidade que leva a pessoa a agir. O sentido é dado pela relação entre o motivo e o objetivo ou resultado previsto para a tarefa. Se houver uma coincidência entre motivo e objetivo, ou seja, se a pessoa atua porque esta interessada, necessitada ou motivada pelo resultado que alcançará no final da tarefa, então a atividade tem um sentido para ela. Em outras palavras, se o resultado da tarefa responde a uma necessidade, motivo ou interesse da pessoa que a realiza, percebemos que a pessoa está inteiramente envolvida em seu fazer: sabendo por que realiza a tarefa e querendo chegar ao seu resultado. Nesse caso, dizemos que ela realiza uma atividade e, ao realizar essa atividade, esta se apropriando das aptidões, habilidades e capacidades envolvidas nessa tarefa. (MELLO, 2004, p. 149).

Portanto, o processo de ensino e aprendizagem é o elemento mais afetado a partir dos dois primeiros núcleos de significados identificados na pesquisa. O distanciamento entre professores e alunos pode prejudicar esse processo que poderá ou não constituir-se uma atividade, ou seja, que o processo de ensino e aprendizagem gere motivação e tenha sentido e significado para os sujeitos envolvidos.

Os dados referentes ao terceiro núcleo de significados - "Relação com o Conhecimento” são mais positivos que negativos, embora figurem como menos frequentes que os primeiros. Neste núcleo os docentes destacaram que os alunos mostram vontade de aprender, são questionadores, curiosos e gostam de discussões, inclusive política. Este reconhecimento convalida os avanços que ocorrem no pensamento durante a idade de transição no plano conceitual, pois o pensamento por conceitos é o núcleo em torno do 
qual se operam as mudanças fundamentais do pensamento que levam a formação da autoconsciência pela qual o sujeito amplia suas possibilidades de compreender o mundo a sua volta, seus nexos e conexões, bem como a si. Este nível não representa um mero amadurecimento orgânico das formas de pensamento anteriores, mas resulta de uma síntese complexa produzida pelo confronto com a vida social e cultural, sendo uma forma superior da atividade intelectual. Neste sentido,

O mundo se apresentará ao adolescente com novas possibilidades, desenvolve-se uma concepção do mundo político-social, favorecida pela maior participação do adolescente na atividade social. [...] Os novos problemas que a vida apresenta ao adolescente exigem formas superiores de pensamento. (LEAL; FACCI, 2014, p. 40).

Isto explica porque o adolescente é questionador e busca explicações sobre as coisas do mundo. Para Vygotski (1996), abre-se diante dele o mundo da consciência social objetiva, pois estão em formação as suas concepções de mundo, de sociedade e de seu lugar na realidade.

O quarto núcleo de significados denominou-se "Nível de Desenvolvimento", no qual registram-se expressões como: falta de maturidade (8), imaturos (6), inconsequentes (4), influenciáveis (3), ligados a opinião da maioria (2), inseguros (2) buscam crescimento (1).

Levando-se em consideração os apontamentos realizados por Vygotsky (1996) de que a idade de transição é marcada pela mudança dos interesses característicos da infância, compreende-se que o processo de desenvolvimento não ocorre de forma linear, sendo caracterizado por avanços e retrocessos que influenciam o comportamento do jovem. Ao analisar respostas que constituem este núcleo de significados, evidencia-se que a caracterização dos estudantes como imaturos revela a ancoragem das concepções docentes na psicologia tradicional, marcadas pelo biologicismo e maturacionismo. Respostas como "influenciáveis" e "ligados a opinião da maioria”, permitem analisar que os adolescentes partilham dos mesmos objetivos sociais que começam a ser construídos por meio da mudança dos interesses, das novas cobranças que o meio impõe a eles. Isto resulta de um mecanismo de comunicação entre os pares que permite ao jovem constituir modos de se relacionar com a nova realidade objetiva e consequentemente essa construção irá modificar também as formas subjetivas do pensamento. Nesse sentido, o comportamento compreendido como influenciável ou ligado a opinião da maioria constitui-se muito mais como um processo de identificação e de busca pela inserção no mundo adulto.

Na analise desse núcleo de significado, evidencia-se uma única resposta de caráter positivo: "buscam crescimento”. A partir dela pode-se pensar a respeito da capacidade do adolescente de estabelecer novos objetivos em relação a sua conduta e buscar modos de alcança-los. Dai a importância da atividade profissional de estudo no desenvolvimento das novas capacidades que o adolescente passa a ter devido a formação das funções psicológicas superiores e do pensamento por conceitos, considerando-se a importância da educação escolar para o adolescente especialmente em relação às suas possibilidades de construir uma consciência social que lhe permita desvelar os nexos existentes por detrás dos fenômenos que fazem parte de sua realidade.

\section{Denominou-se "Perspectivas de} Futuro" o quinto núcleo de significados extraídos dos registros feitos pelos professores ao tratarem dos seus jovens estudantes. Neste núcleo agruparam-se representações sobre: falta de oportunidade (6), sem perspectiva 
de trabalho remunerado (4), esperançosos (4), pessoas sem perspectivas (4), busca de independência (3), perspectiva de ingressar em curso superior (2), sem futuro (1). Tais expressões acerca do futuro dos estudantes da escola pública são tristemente contraditórias, pois retratam certas antecipações feitas pelos professores ao considerarem a sociedade em que se vive e suas demandas. De um lado representam o universo dos sonhos dos estudantes (ingresso num curso superior, esperanças, independência), de outro carregam a perversidade da sociedade capitalista (falta de oportunidades, de perspectivas e de futuro), em que os meios de produção estão apartados e distanciados dos sujeitos que os produzem. Trata-se, assim de uma compreensão, ainda que intuitiva, acerca do provável destino social do jovem da escola pública, que provém invariavelmente das classes populares, o qual "Mutilado de suas condições de existência, [...], submete-se às relações capitalistas de produção como trabalhador em busca de sobrevivência”. (ROMAN; SOUZA, 2014, p. 179).

O adolescente que está no ensino médio nas escolas públicas pode ser considerado um sobrevivente do sistema educacional e social, para o qual a escola representa uma única oportunidade de ascensão social e/ou, pelo menos de manutenção da vida, mesmo humilde. Por sua origem social e econômica é desprovido dos meios de produção. Não fosse assim não necessitaria da escola pública. A educação escolar é, pois, muito significativa para o seu aprendizado e desenvolvimento, que oferece a ele as categorias conceituais mais abstratas necessárias ao entendimento do mundo e suas relações. Por meio da transmissão de conhecimentos científicos própria da escola ele pode desenvolver funções psíquicas mais elaboradas que não se desenvolveriam se deixadas ao sabor da experiência prática, cotidiana.
O núcleo de significados denominados "Relacionamento Afetivo", compõem-se de registros feitos pelos professores que aludem aos seguintes termos: carentes (4), desconfiados (4), sem base familiar (3), amizades (2), alegres (2) e festeiros (1).

A perspectiva vygotskiana coloca questões como as amizades em evidência ao afirmar que a comunicação íntima com os pares, além do estudo como preparo profissional, representa uma atividade preponderante na idade de transição. Este tipo de atividade não se refere unicamente ao namoro ou atração pelo sexo oposto, mas refere-se, sobretudo ao que a psicologia tradicional costuma chamar de "tendência grupal”, ou seja, as atividades entre os pares configuradas em amizades, festas, momentos de alegria e até mesmo a partilha da confiança/desconfiança e possíveis manifestações de carência afetiva. Como dizem Mascagna e Facci (2014, p. 55): “O jovem gosta de estar junto com o grupo de amigos, de conversar e de sair com eles”.

Tudo isto é favorecido pela frequência à escola, espaço institucional em que o contato com os pares é cotidiano e dentro do qual cada adolescente pode discutir ideais, valores e soluções para os problemas que já percebe no mundo, ainda que seja apenas em imaginação. $\mathrm{O}$ adolescente está adentrando a um novo universo de relações e objetivos sociais, mas seus desejos e aspirações ainda ficam a margem de uma situação concreta. Portanto, a importância da atividade de comunicação íntima com os pares explica-se pelo fato de que o adolescente não participa ainda das atividades sociais características do meio humano adulto, embora possa ter um crescimento físico/ biológico bastante aproximado aos adultos. Isto gera muitos dos conflitos que se mostram na idade de transição e que resultam não de uma turbulência natural e esperada, mas do descompasso entre aquilo que imagina e aspira para si, seus desejos e sonhos, e a percepção 
das possibilidades e ações reais necessárias à sua concretização. Assim, "seus ideais permanecem no mundo dos sonhos e não coincidem com suas ações reais, dirigidas à sua realização.” (MASCAGNA; FACCI, 2014, p. 55). Desconfianças, carências, inseguranças, negativismos, oposições, que se mostram no campo da afetividade nos adolescentes, possuem, portanto, origem social e não são características universais e naturais da fase de transição.

Considera-se ao final destas análises a importância de os professores que trabalham com adolescentes romperem com os estereótipos sobre a adolescência e construírem referenciais focados na compreensão histórico-cultural dos estudantes da escola pública.

\section{Considerações finais}

Em pesquisa desenvolvida por Checchia e Souza (2014) sobre as tensões e desafios nas relações entre educadores e estudantes adolescentes é interessante o dado apresentado de que a representação construída dos educadores em relação aos seus educandos está relacionada a visão que os próprios adolescentes constroem de seus educadores. As pesquisadoras explicam que os professores que possuem visões depreciativas de seus educandos também são criticados pelos próprios alunos, ao passo que os adolescentes também representam diferentemente professores que não possuem essa visão.

Esta análise faz refletir que quando os professores, nesta pesquisa, apontam elementos referentes ao comportamento do aluno, motivação para aprendizagem e relação com o conhecimento podem estar indicando uma relação de expectativas na direção do docente ao aluno, mas também do aluno ao docente.

Considerando a abordagem histórico-cultural como fundamento de análise, entende-se que o estudante da escola pública é um sujeito constituído histórica e socialmente, a partir de vivências que os marcam por meio de sentidos e significados. Tanto os discursos dos professores, bem como a maneira como o aluno se apresenta para eles, apresentam inúmeros elementos complexos que devem ser considerados, os quais certamente ultrapassariam o escopo deste texto.

Assim, a guisa de uma finalização para este artigo, julga-se valioso destacar que a mudança do lugar social do adolescente configurada sobretudo pela mudança nas relações com as pessoas de seu mundo, ao lado do desenvolvimento em curso da autoconsciência e da ideologia de classe são fatores determinantes das relações que estes estabelecem com os adultos no seio de uma dada sociedade.

A ideia de adolescência concebida como fase natural de turbulências, oposições, rebeldias, autoafirmações, tal como propagada na psicologia tradicional, confere à adolescência o status de um fenômeno dado, pronto e universal, o qual esconde a sua construção histórica e as marcas da sociedade capitalista no desenvolvimento destes jovens. É no seio de uma sociedade desigual que os jovens das classes populares se desenvolvem, ao mesmo tempo excluídos dos processos de humanização, ao mesmo tempo chamados a aderir a ordem estabelecida: a ordem do trabalho alienado e subalterno, a ordem da exploração das massas e do lucro de quem detém a posse dos meios de produção. Assim também a ordem do consumo desenfreado, do imediatismo e individualismo presentes no todo social.

As representações negativas e depreciativas dos adolescentes portadas pelos participantes da pesquisa são consoantes a visão de educação como disciplinamento e conformação, contribuindo para os processos de exclusão que se operam na sociedade de classes, dominada pela ideologia do mérito 
e da difusão da liberdade individual. Daí a necessidade de imprimir na formação dos professores uma perspectiva crítica, que enfatize a complexidade e multideterminação dos fatores implicados no processo educacional e a necessária ruptura da imagem socialmente atribuída ao adolescente da escola pública.

\section{Referências}

ALEVATO, H. M. R. Qualidade: um mito pós-moderno. In: TEVES, N.; RANGEL, M. (Org.) Representações sociais e educação: temas e enfoques contemporâneos de pesquisa. Campinas: Papirus, 1999. p. 79114.

ALVES-MAZZOTTI, A. J. Representações sociais: aspectos teóricos e aplicações à educação. Revista Múltiplas Leituras, São Paulo, v. 1, n.1, p.18-43, jan/jun, 2008.

ANJOS, R. E. O desenvolvimento psíquico na idade de transição e a formação da individualidade para si: aspectos teóricos para a educação escolar de adolescentes. 2013. 168 f. Dissertação (Mestrado em Educação Escolar) - Universidade Estadual Paulista, Faculdade de Ciências e Letras, Campus Araraquara, 2013. Disponível em: < http://repositorio.unesp.br/bitstream/ handle/11449/97430/anjos_re_me_arafcl. pdf? sequence $=1>$. Acesso em: 20 abr. 2016.

AVILA, S. F. O. A adolescência como ideal social. In: SIMPÓSIO INTERNACIONAL DO ADOLESCENTE. 1., 2005, Rio de Janeiro. Resumos... Rio de Janeiro. Faculdades integradas Maria Theresa e Centro Universitário Metodista Unibennetti, 2005. Disponível em: <http://www. proceedings.scielo.br/scielo.php?pid=MS C0000000082005000200008\&script $=$ sci_ arttext>. Acesso em: 20 jan. 2016.
BOCK, A. M. B.Aperspectiva sócio-histórica de Leontiev e a crítica à naturalização da formação do ser humano: a adolescência em questão. Cadernos Cedes, Campinas, v. 24, n. 62, p. 26-43, abril, 2004.

BOCK, A. M. B. A adolescência como construção social: estudo sobre livros destinados a pais e educadores. Revista Semestral da Associação Brasileira de Psicologia Escolar Educacional (ABRAPAE). São Paulo, v. 11, n. 1. jan./jun. 2007. Disponível em: < http://www.scielo. br/pdf/pee/v11n1/v11n1a07>. Acesso em: 03 fev. 2016.

CHECCHIA, A. K. A.; SOUZA, M. P. R. de. Adolescência e escolarização: tensões e desafios nas relações pedagógicas entre educadores e estudantes. In: LEAL, Z. F. R.; FACCI, I. M. G. D.; SOUZA, M. P. R. (Orgs.). Adolescência em foco: contribuições para a psicologia e para a educação. Maringá: EDUEM, 2014. p. 103-122.

CRUZOÉ, N. M. de C. A teoria das representações sociais em Moscovici e sua importância para a pesquisa em educação. APRENDER - Caderno de Filosofia e Psicologia da Educação, Vitória da Conquista, n.2. p. 105-114, 2004.

GUARESCHI, P. Representações sociais: alguns comentários oportunos. In: NASCIMENTO-SCHULZE, C. M. (Org.) Novas contribuições para a teorização e pesquisa em representação social. Florianópolis: UFSC, 1996. p. 9-35.

JODELET, D. Representações sociais: um domínio em expansão. In:

Representações sociais. Rio de Janeiro: EDUERJ, 2001. p. 17-44.

Représentations sociales: un domaine en expansion. In: __. Les representations sociales. Paris: PUF, 1989. 
p. 31-61. Tradução: Tarso Bonilha Mazzotti. Revisão Técnica: Alda Judith AlvesMazzotti. UFRJ-Faculdade de Educação, dez. 1993.

JOVCHELOVITCH, S. Representações sociais: para uma fenomenologia dos saberes sociais. Psicologia e Sociedade, Belo Horizonte, v.10, n. 1, p. 54-68, 1998.

KOSHINO, I. L. A. Vigotski: desenvolvimento do adolescente sob a perspectiva do materialismo histórico e dialético. 2011. 133 f. Dissertação (Mestrado em Educação). Universidade Estadual de Londrina, Londrina: Paraná, 2011.

LEAL, Z. F. R.; FACCI, I. M. G. D. Adolescência: superando uma visão biologizante a partir da psicologia Históricocultural. In: LEAL, Z. F. R.; FACCI, I. M. G. D.; SOUZA, M. P. R. (Orgs.). Adolescência em foco: contribuições para a psicologia e para a educação. Maringá: EDUEM, 2014. p. $15-44$.

LAROCCA, P.; MACHADO, E. R.; PRACHUM, B. N.; SANTOS, N. Compreensões da adolescência para a formação de professores: buscando abordagens baseadas na Psicologia Histórico Cultural. (Projeto de pesquisa). Universidade Estadual de Ponta Grossa. Ponta Grossa, Paraná, 2014.

LURIA, A. R. Curso de psicologia geral v. 1: introdução evolucionista à psicologia. Rio de Janeiro: Civilização Brasileira, 1979.

MASCAGNA, G. C.; FACCI, M. G. D. A atividade principal na adolescência: uma análise pautada na psicologia históricocultural. In: LEAL, Z. F. R.; FACCI, I. M. G. D.; SOUZA, M. P. R. (Orgs.). Adolescência em foco: contribuições para a psicologia e para a educação. Maringá: EDUEM, 2014. p. $45-70$.
MELLO, S. A. A Escola de Vygotsky. In: CARRARA, K. (Org.). Introdução à Psicologia da Educação: seis abordagens. São Paulo: Avercamp, 2004.

MENIN, M. S. de S.; SHIMIZU, A. de M.; LIMA, C. M. de. A teoria das representações sociais nos estudos sobre representações de professores. Cadernos de Pesquisa, São Paulo, v. 39, n.137, p. 549-576, maio/ago., 2009.

REIS, S. L. de A. ; BELLINNI, M. Representações sociais: teoria, procedimentos metodológicos e educação ambiental. Teoria e Prática da Educação, Maringá. v. 33, n. 2, p. 149-159, 2011.

ROMAN, M. D.; SOUZA, M. P. R. de. Psicologia e direitos humanos: a adolescência em conflito com a lei em foco. In: LEAL, Z. F. R.; FACCI, I. M. G. D.; SOUZA, M. P. R. (Orgs.). Adolescência em foco: contribuições para a psicologia e para a educação. Maringá: EDUEM, 2014. p. 159184.

SÁ, C. P. de. Representações sociais: o conceito e o estado atual da teoria. In: SPINK, M. J. (Org.) O conhecimento no cotidiano: as representações sociais na perspectiva da psicologia social. São Paulo: Brasiliense, 1993. p. 19-45.

SÊNA, R. A. O conceito de representação social nas obras de Denise Jodelet e Serge Moscovoci. Anos 90, Porto Alegre, v. 8, n. 13, p. 128-133, jul. 2000. Disponível em: <http:// www.ufrgs.br/ppghist/anos90/13/13art8. pdf $>$. Acesso em: 4 de set. de 2015.

SALOMONE, R. Entre o universal e o particular: o desafio da práxis pedagógica em escolas de meios populares. In: RANDOLPHO, A.; BURGOS, M. B. A escola e a favela. Rio de Janeiro: Ed. PUCRio: Ed. Pallas, 2009. 
SERGIO, L. Trabalho e proletariado no capitalismo contemporâneo. São Paulo: Cortez, 2007.

SPINK, M. J. P. O conceito de representação social na abordagem psicossocial. Cadernos da Saúde Pública, Rio de Janeiro, v. 9, n. 3, p. 300-308, jul/set, 1993.

TOMIO, N.; FACCI, M. G. D. Adolescência: uma análise a partir da psicologia sóciohistórica. Revista Teoria e Prática da Educação, Maringá, v. 12, n. 1, p. 89-99, jan./abr. 2009.

VYGOTSKI, L. S. Obras escogidas IV. Primeira parte: Paidologia del adolescente. Edição em língua castelhana. Madrid: Visor Dis, 1996. 